\title{
NOSTALGIA ZA KLASYKĄ W POWIEŚCI MANARAGA WŁADIMIRA SOROKINA
}

\section{NOSTALGIA FOR THE CLASSIC IN THE NOVEL MANARAGA BY VLADIMIR SOROKIN}

\author{
ANNA STRYJAKOWSKA
}

\begin{abstract}
AвSTRACт. The article discusses Vladimir Sorokin's novel Manaraga as a metafictional statement concerning the problem of the literary canon. The proposed interpretation places the novel in the post-ironic thinking, within which the value of high culture is still in force.

Keywords: Vladimir Sorokin, literary canon, metafiction, post-irony

Anna Stryjakowska, Uniwersytet im. Adama Mickiewicza w Poznaniu, Poznań - Polska, a.stryjakowska@gmail.com
\end{abstract}

ORCID ID: 0000-0001-9429-2849

W wydanej w 2017 roku powieści Manaraga (ros. Maнapaza) Władimir Sorokin kontynuuje znaną z wcześniejszych dzieł futurologiczną refleksję o Europie. Centralny wątek utworu ma charakter jawnie metarefleksyjny i sytuuje się w kręgu Sorokinowskiej afirmacji literatury, zagadnienia akcentowanego choćby w powieści Голубое сало czy dramacie Dostoevsky-Trip. Niniejszy artykuł stanowi próbę analizy powieści w kontekście kategorii nostalgii, której obiektem staje się w danym wypadku klasyka literatury rosyjskiej.

Akcja utworu rozgrywa się w 2037 roku w Europie odbudowującej się po wojnie z fundamentalistycznym muzułmańskim najeźdźcą. Książka stała się w tych realiach przedmiotem deficytowym: większość światowych zasobów celowo zniszczono, a pozostałe dziesięć procent umieszczono w muzeach i bibliotekach pod ścisłym nadzorem. Wykształtował się jednak nowy, nielegalny proces ich wykorzystania - procedura zwana book'n'grill. Polega ona na widowiskowym przyrządzaniu potraw na ogniu powstającym w wyniku spalania książek; jest to rodzaj elitarnej rozrywki oferowanej bogatym klientom z całego świata. Procesem kierują kucharze, skupieni w organizacji zwanej Kuchnią, która za pośrednictwem specjalnych bookinistów wykrada, często z użyciem przemocy, egzemplarze książek zdeponowane w bibliotekach. Jednym z kucharzy jest protagonista i zarazem narrator - Geza Jasnodworski, urodzony w rodzinie białoruskiego Żyda i polskiej Tatarki, którzy uciekli przed fundamentalizmem religijnym do Budapesztu. Geza kreuje siebie na 
wielkiego miłośnika literatury; nieco ironicznie nawiązując do swojej profesji, zwraca on uwagę na wręcz energetyczny związek między czytelnikiem a tekstem: „Все-таки книга - это целый мир, хоть и ушедший навсегда. В этом смысле я романтик. [...] И я знаю точно - если ты любишь книгу по-настоящему, она отдаст тебе все свое тепло" [Сорокин 2017]. Specjalnością bohatera jest klasyka literatury rosyjskiej; czytelnik raczony jest scenami kolejnych seansów grillowania potraw na wybranych dziełach, a klienci za każdym razem przypominają bohaterów tych dzieł - można owe fragmenty postrzegać jako próbki talentu stylizacyjnego Sorokina. Fabuła nabiera rozpędu gdy wychodzi na jaw działalność szkodliwej dla Kuchni fabryki, produkującej ogromne ilości idealnych kopii arcydzieł (fabryką kieruje Henri, zdrajca Kuchni); jest to działalność nastawiona na legalizację i umasowienie rozrywki book'n'grill. Wierny ideom elitaryzmu i romantycznemu etosowi podziemia Geza otrzymuje zadanie dotarcia do szkodników i zutylizowania wyprodukowanego nakładu Ady Vladimira Nabokova.

W centrum problematyki utworu znajduje się zagadnienie władzy nad kanonem literackim i obrony podziału na literaturę wysoką i niską - taką optykę w równie interesującej co zgryźliwej recenzji powieści proponuje krytyk Lew Daniłkin [Данилкин 2018]. Kuchnia widzi siebie jako organizację wysoce elitarną, ściśle profesjonalną, wypełniającą swego rodzaju misję troski o czystość literackiego kanonu. Niektóre rodzaje literatury uznawane są za niekanoniczne, nienadające się do procedury book'n' grill; pojawia się zapisywana często kursywą leksyka normatywna: „канонические дрова”, „"правильные книги”, „правильно читать”. Poza obowiązujący kanon zostaje wykluczona choćby najnowsza literatura tworzona przez amatorów kierowanych chęcią wypowiedzenia wojennej traumy (nie istnieje ona $\mathrm{w}$ formie papierowej, ale też nie ma w Kuchni zainteresowania jej zapisem i ewentualnym użyciem do grillowania); ponad to nieakceptowane są zwykle wprawki literackie autorstwa samych klientów Kuchni, którzy starają się naśladować klasyków:

На Кухне вообще не любят самозванцев. Периодически возникают новые флоберы, достоевские или кафки и требуют обслужить их, приходя к нам со своими дровами. Беда в том, что это - не канонические дрова, а новый валежник, выращенный ими на своем огороде. Кухня нужна им для легитимации в собственных глазах и среди окружающих их безумцев. Но Кухня строго блюдет канон. Хотя на некоторых, как, например, на норвежского Толстого, Кухня смотрит сквозь пальцы. Бывают, бывают исключения [Сорокин 2017].

Główny bohater stosuje jeszcze bardziej rygorystyczne kryteria oceny jakości literatury. Pewne jego sympatie w tym zakresie wydają się śladem gustu samego autora - ponownie już w twórczości Sorokina dokonuje się 
krótkie i bezlitosne potępienie stylu Maksyma Gorkiego: „я люблю русскую классику [...]. И я не буду жарить стейк на писателе второго сорта, вроде Горького" [Сорокин 2017]. Jeszcze większą dezaprobatę Geza wyraża wobec literatury zwanej w powieści poradziecką, której jaskrawą egzemplifikacją czyni Sorokin utwór nawiązujący do Sańkji Zachara Prilepina. Zakup tego i kilku innych dzieł zostaje protagoniście zaproponowany przez znajomego, po lekturze fragmentów zniesmaczony Geza jednak odmawia:

На автостоянке ко мне подходит Борис, почитывающий на советской литературе. Он часто мне предлагает что-нибудь не очень съедобное. Но я не в обиде. [...] В руках у густо усатого Бориса сумка с книгами. - Глянь, Геза. Это постсоветская литература. Отдаю всю вязанку - за пару штук. Здесь пять авторов. Беру наугад неувесистое поленце: „Я пришел с Родины”. На обложке - бритоголовый автор с проспиртованным взглядом. Листаю. [...] Возвращаю: - Нет, на таком не жарю. Ты же знаешь, наш век - не мое чтение. Предложи македонцам. У них в горах есть клиентура на постсоветский валежник [Сорокин 2017].

Mamy zatem do czynienia z wymownym gestem odrzucenia najnowszej literatury hiperrealistycznej, tzw. czernuchy. Nie podlega natomiast dyskusji wysoki status takich klasyków, jak Fiodor Dostojewski, Antoni Czechow, Mikołaj Gogol, Isaak Babel, a z literatury zachodniej - François Rabelais, Gustave Flaubert, James Joyce, Virginia Woolf. Arcydziełem wiodącym jest zaś w powieści wspomniana Ada Nabokova, przedstawiana jako szczególnie kosmopolityczne dzieło modernisty. Podkreślić należy, że Henri - zdrajca Kuchni i zwolennik umasowienia book' $n^{\prime}$ grill - nie proponuje $\mathrm{w}$ zakresie kanonu żadnych znaczących zmian (poza uzupełnieniem go o księgi sakralne). Zatem kanonu literatury światowej, pojmowanego analogicznie do dzisiejszych kryteriów, strzegą w powieści oba ośrodki władzy (wraz z elitą klientów), usuwając na margines zjawiska tych kryteriów niespełniające. Tak zarysowana szarża przeciwko mierności najnowszej literatury nie spodobała się Daniłkinowi, który zarzuca Sorokinowi anachroniczność i naiwną arystokratyczną reakcyjność - wszak władza (również polityczna) jest już, wedle słów krytyka, w rękach barbarzyńców i protest rzekomo nie ma sensu [Данилкин 2018]. Podzielając smutną diagnozę rzeczywistości politycznej, a nawet zgryźliwą uwagę o nieprzystawalności Manaragi do pojęcia arcydzieła, nie mogę przychylić się do sedna formułowanych zarzutów i na mocy powyższych przesłanek kwestionować prawo Sorokina do nostalgicznej manifestacji własnego stanowiska. Wolno bowiem ową $\mathrm{w}$ istocie niewybitną powieść postrzegać jako interesujący metanamysł nad zagadnieniem kanonu, gest rewitalizacji klasyki, odsłonięcie - choćby poprzez opisy zachowania klientów Gezy - antropologicznego potencjału fikcji, wreszcie - subiektywną interwencję etyczną, obronę sensu wartościowania dzieł literackich. 
W tym aspekcie ciekawym teoretycznym kontrapunktem do powieści Manaraga wolno uczynić rozważania Arkadiusza Żychlińskiego towarzyszące jego wizji filologii jako „laboratorium antropofikcji”, czyli badania fikcji jako studiów ludzkiego doświadczenia. Polski filolog opowiada się, podobnie jak Sorokin, za wartościowaniem, jako kryteria wskazując, sprzężone ze sobą, stopień koncentracji prawdy egzystencjalnej i talent twórcy:

W zasadzie wszystkie fikcje zajmują się człowiekiem [...] - niektóre traktują o nim w sposób pełniejszy i bogatszy niż inne; te właśnie nazywam antropofikcjami, czyli fikcjami, z pomocą których człowiek orientuje się, co znaczy być człowiekiem [Żychliński 2014: 23-24].

Niezależnie od medium to talent twórcy jest gwarantem poznawczej efektywności (wizja stanowi poręczenie wglądu). Słabe powieści, słabe wiersze, słabe filmy, słabe seriale czy słabe gry nie dlatego są kiepskie, że to powieści, wiersze, filmy, seriale czy gry, lecz dlatego, że ich twórca czy twórcy niewiele mieli do powiedzenia. Instynkt narracyjny sprawia, że jesteśmy głodni opowieści - ale gros historii konsumowanych na co dzień to oczywiście narracyjne fast foody [Żychliński 2014: 34].

Odwołanie do żywieniowej metafory wydaje się szczególnie bliskie narracji Manaragi. Powieść Sorokina jawi się w nakreślonym kontekście jako paralelna wobec teorii metarefleksyjna deklaracja przywiązania do hierarchicznej percepcji wypowiedzi artystycznych.

Odwrót od postmodernistycznego zatarcia granic i legitymizacja pewnych opozycji nie oznacza rezygnacji z charakterystycznego dla twórczości Sorokina dystansu, ironii, autoironii, eksponowania ambiwalentności zjawisk, swobodnej gry z kanonem. W sposób jawnie parodyjny kreowana jest w powieści instytucja Kuchni, wraz ze swoją hierarchią, hermetycznością, poczuciem misji, branżowymi obyczajami i sprzeczkami, specyficznym żargonem. Organizowany przez nią book'n' grill rysuje się cokolwiek dwuznacznie. $Z$ jednej strony jest on zręczną metaforą nobilitującą proces lektury jako przepływu energii między dziełem a odbiorcą, a więc swego rodzaju mitologizacją rytuału czytania. Z drugiej strony book'n'grill wiedzie de facto do zniszczenia cennych egzemplarzy książek - trudno wobec tego zgodzić się z uwagą Antona Dolina, że zachodzi tu dokładne odwrócenie sytuacji z dystopii Raya Bradbury'ego 451 stopni Fahrenheita [В России настоящеe] - u Sorokina palenie książek co prawda przywraca im wartość i wydobywa energię, jednak tylko na moment. Ponadto nielegalne pozyskiwanie cennych pozycji $\mathrm{z}$ bibliotek obarczone jest przemocą, $\mathrm{w}$ czasie kradzieży niekiedy giną ludzie. Przeciwko rozbojom i niszczeniu książek protestuje zresztą oświecona część powieściowego społeczeństwa, oficjalnie book'n'grill ogłoszono przestępstwem przeciwko kulturze i cywilizacji. W tym aspekcie alternatywa rysowana przez Henri wydaje się daleko bardziej humanitarna i demokratyczna - 
legalizuje bowiem ów osobliwy biznes i umożliwia kontakt z energią klasyki szerszym masom. Otwartym pozostaje jednak pytanie, czy jest to właściwe remedium w obliczu kryzysu samej idei book'n'grill - coraz mniej popularnej i degradującej się również wobec obniżającego się poziomu samych kucharzy. Jeśli przyjąć za prawdziwą diagnozę Henri, w zakończeniu utworu instytucja Kuchni jawi się czytelnikowi jako niesłusznie zapatrzony w siebie kolos na glinianych nogach.

Wysoce ambiwalentna jest ponadto centralna postać Gezy. Obok efektownej autokreacji na wyrafinowanego czytelnika bohater odsłania swoje niekiedy pokaźne luki w wiedzy i trywialność zainteresowań. Tryb życia, naznaczony dreszczykiem ryzyka, sytuuje Gezę w kręgu bohaterów kina akcji - Manaraga karmi się zresztą tą estetyką, przywołując na myśl powieść 23000, trzecią część „lodowej” Trylogii Sorokina [Сорокин 2006]. Z uwielbianą przez siebie rosyjską klasyką protagonista zapoznał się nie samodzielnie, lecz za pośrednictwem sztucznej inteligencji - ten fenomen uobecniają $\mathrm{w}$ powieści mądre pchły, organizujące znaczną część życia intelektualnego oraz kwestie logistyczne. Opisane wyżej normatywne sądy nie zostały zatem wypracowane $\mathrm{w}$ toku autonomicznej refleksji, lecz wkomponowane $\mathrm{w}$ umysł bohatera przez zewnętrzny byt:

А я люблю русскую классику, хотя не прочел и до середины ни одного русского романа. [...] Всю классику я и моя умная блоха знаем наизусть: сюжет, биография автора со всеми подробностями, дата выхода бумажного полена. Это необходимо знать каждому повару, даже если он вообще не умеет читать книги. А таких людей у нас, к сожалению, все больше. Хотя, безусловно, чтобы хорошо прочесть книгу, повару необязательно ее прочесть. Парадокс XXI века. „O tempora, o mores!" - как говаривал мой покойный профессор-отец [Сорокин 2017].

Można więc w Gezie widzieć figurę hipokrytycznego czytelnika-tradycjonalisty, fałszywie tęskniącego za wartością tak naprawdę nieznaną. Wysunięte przez pewną grupę rozczarowanych klientów oskarżenie Gezy o uzurpatorstwo okazuje się w tym kontekście poniekąd słuszne. Dokonywana przez Sorokina afirmacja klasyki nabiera więc charakteru nostalgicznego nie tyle w zestawieniu z rzeczywistością pozaliteracką, co w świetle formułowanej w tekście prognozy dewaluacji kontaktu z książką i samodzielności myślenia. Odnotować należy również fakt, że Geza wydaje się postacią chwiejną, konformistyczną, interesowną, na co wskazywałoby zakończenie utworu, przynoszące entuzjastyczne poparcie Gezy dla umasowienia gotowania - również ta zmiana poglądów jest wszakże następstwem wszczepienia odpowiednich pcheł, programujących umysł bohatera.

Nie podlega wreszcie wątpliwości hermetyczność kreowanej w powieści afirmacji klasyki - Sorokinowska nostalgia nie ukrywa, że jest sentymentalną 
nostalgią upadających elit, a wręcz wydaje się naświetlać problematyczność tego zjawiska poprzez znaczącą nieobecność w utworze czytelnika masowego. O ile dziełem przeszłości jest drukowanie książek i ich tradycyjna lektura, o tyle książka jako taka istnieje dalej w postaci hologramów; kontakt z literaturą nie ogranicza się do fenomenu book'n' grill, dostępnego tylko dla bogatych. Tajemnicą pozostaje przy tym pozycja klasyki oraz tzw. literatury drugiego sortu w społeczeństwie przyszłości. Znamy gusta kucharzy i wybranej grupy klientów, niewiele dowiadujemy się o sympatiach przeciętnego czytelnika. Pewnym optymistycznym sygnałem mogą być natomiast nakreślone w powieści preferencje szerokiej publiczności odnoście do obrazów filmowych (określanych mianem „holo"):

\begin{abstract}
Плоский кинематограф, как известно, уперся в перепроизводство цифровых чудес: монстры, динозавры, путешествие по галактикам, фантастические превращения надоели человечеству, и оно взалкало человеческого размера. Особенно после войны. Зрители захотели земных чувств. Что империя Holo и предоставила. Фантастических holo теперь вообще производится крайне мало. Люди соскучились по простым историям: любовь, радость душевная и телесная, ревность, религиозная экзальтация, преступления, саспенс, хорор, семейный уют. Действие ограничено земным пространством. Жанрово преобладают комедии. И классика, конечно, получившая визуальный и чувственный объем [Сорокин 2017].
\end{abstract}

Opisywane zmęczenie fantastyką i głód realizmu nasuwa na myśl obserwowane dzisiaj zapotrzebowanie na referencyjność, przekracza jednak trend non-fiction, wyraźnie dostrzegając wartość fikcji jako nośników prawdy egzystencjalnej, wiedzy antropologicznej. Obraz odbiorcy fikcji pozostaje wszelako obrazem fragmentarycznym.

W podsumowaniu niniejszej refleksji należy podkreślić, iż zaznaczony w opisie kinomanów zwrot antropologiczny ujawnia się również w drodze twórczej samego autora Manaragi. Warto w tym aspekcie odwołać się do sposobu kreacji świata przedstawionego w powieści, który potwierdza pozycję Sorokina jako autora postironicznego, deklarującego przywiązanie do określonego zespołu wartości. Fundamentem tego etosu jest oczywiście omówiony tu literaturocentryzm narracji. Wśród innych wartości konstytutywnych wymienić należy wolność, humanitaryzm, heterogeniczność, tolerancję, sprzeciw wobec przemocy. Futurologiczny świat Sorokina to tradycyjnie świat wysoce różnorodny i kosmopolityczny. Występują w nim m.in. bohaterowie zoomorficzni, postaci o niecodziennej konstrukcji cielesnej; ekscentryczność wydaje się postawą powszechną; kosmopolityzm budują choćby mylące imiona bohaterów, oderwane od ich pochodzenia etnicznego. Nie jest ów świat pozbawiony antywartości: chociaż widmo fundamentalizmu religijnego udało się odsunąć w wyniku zwycięskiej wojny, jej pokłosiem stała się 
wszechobecna przemoc; na porządku dziennym jest rozwiązywanie konfliktów poprzez bójki - główny bohater przygląda się temu nie bez smutku, sam jednak działa w organizacji korzystającej z metod siłowych. Na rzecz refleksji egzystencjalnej znacznie ogranicza Sorokin eksperyment formalny, proponując klasyczną powieść silnie czerpiącą z konwencji fikcji popularnych. Już tylko na zasadzie puszczenia oka do czytelnika nawiązuje do swej dawniejszej skłonności do gier językowych, np. w nazwie gry OBOROBO-3 czy językowym bełkocie tracącego przytomność Gezy. Nienachalna i świadoma swych ograniczeń interwencja etyczna, zawieszenie postmodernistycznej ironii w sprawach fundamentalnych, antropologiczny zwrot sytuują twórczość Sorokina w kręgu kultury postpostmodernistycznej, zmęczonej terrorem ironii [Wallace 2016: 102-103] i powracającej ku ludzkiemu doświadczeniu.

\section{Bibliografia}

«В России настоящее стало будущим, а будущее слилось с прошлым» Владимир Сорокин о своей новой книге «Манарага» (2017). (интервью А. Долина с В. Сорокиным), źródło elektroniczne: https://meduza.io/feature/2017/03/10/v-rossii-nastoyaschee-stalo-buduschim-a-buduschee-slilos-s-proshlym (dostęp 12.09.2017).

Данилкин Л. 2018. О чем на самом деле «Манарага» Владимира Сорокина: объясняет Лев Данилкин, źródło elektroniczne: https:/ / daily.afisha.ru/brain/4792-o-chem-na-samomdele-manaraga-vladimira-sorokina-obyasnyaet-lev-danilkin/ (dostęp 12.09.2017).

Сорокин В. 2006. Трилогия, Москва: Захаров.

Сорокин В. 2017. Манарага, Москва: Corpus, źródło elektroniczne: https:/ /www.litres. $\mathrm{ru}$ /vladimir-sorokin/manaraga/ (dostęp 26.07.2017).

Wallace D. F. 2016. Rzekomo fajna rzecz, której nigdy nie zrobię. Eseje i rozważania, przeł. J. Kozak, Warszawa: W.A.B.

Żychliński A. 2014. Laboratorium antropofikcji. Dociekania antropologiczne, Warszawa-Poznań: Instytut Badań Literackich PAN - Wydawnictwo Naukowe UAM. 
